Article

\title{
The Use of Artificial Intelligence and Deep Learning in Medi- cal Imaging: A Nationwide Survey of Trainees in Saudi Arabia
}

Ahmad A. Mirza ${ }^{1,2, *}$ MBBS MSc, Omar M. Wazgar ${ }^{3}$ MBBS, Amaar A. Almaghrabi ${ }^{4}$ MBBS, Roaa M. Ghandour ${ }^{5}$ MBBS, Sarah A. Alenizi ${ }^{6}$ MBBS, Khalid S. Alraddadi ${ }^{7}$ MBBS SBFM ABFM MMedEd MPH DTQM, Abdulrahim A. Mirza ${ }^{8}$ MBBS, Fayzah H. Al-Adwani ${ }^{9}$ MBBS SBFM ABFM, Mohammed A. Alsakkaf ${ }^{10}$ MBBS SBGS, Yahea A. Alzahrani ${ }^{11}$ MBBS

\footnotetext{
${ }^{1}$ Department of Otolaryngology-Head and Neck Surgery, Faculty of Medicine in Rabigh, King Abdulaziz University, Jeddah, Saudi Arabia. ORCID: 0000-0001-6035-9566. aamirza1@kau.edu.sa

2 Department of Otolaryngology-Head and Neck Surgery, Temerty Faculty of Medicine, University of Toronto, Toronto, ON, Canada. ORCID: 0000-0001-6035-9566. aamirza1@kau.edu.sa

${ }^{3}$ Department of Radiology, Al-Hada Armed forces hospital, Taif, Saudi Arabia. omarwazgar@gmail.com

${ }^{4}$ Department of Radiology, Al-Noor Specialist Hospital, Makkah, Saudi Arabia. ama@outlook.com

${ }^{5}$ Department of Radiology, King Abdullah Medical Complex, Jeddah, Saudi Arabia. roaamg@yahoo.com

${ }^{6}$ Department of Radiology, King Fahad Armed Forces Hospital, Jeddah, Saudi Arabia. alanzirah15@gmail.com

7 Department of Primary Health Care, National Guard Health Affairs, King Saud bin Abdul-Aziz University for Health Sciences, Jeddah, Saudi Arabia.dkraddadi@gmail.com

${ }^{8}$ Department of Surgery - Division of Urology, King Abdulaziz Medical City, Ministry of National Guard Health Affairs, Jeddah, Saudi Arabia. a.mirza992@hotmail.com

${ }^{9}$ Department of Primary Health Care, National Guard Health Affairs, King Saud bin Abdul-Aziz University for Health Sciences, Jeddah, Saudi Arabia. adwanif@yahoo.com

${ }^{10}$ Department of Surgery, Security Forces Hospital Program, Makkah, Saudi Arabia. m.saggaf@hotmail.com

${ }^{11}$ Department of Medicine, College of Medicine, Taif University, Taif, Saudi Arabia. dr.yahea@gmail.com

* Correspondence: aamirza1@kau.edu.sa
}

\begin{abstract}
Artificial intelligence is dramatically transforming medical imaging. We assessed the levels of artificial intelligence use among radiology trainees and explored their perceived impact of artificial intelligence on the radiology workflow and radiology profession, in correlation with the perceived ease of use and behavioral intention to use artificial intelligence. This cross-sectional study enrolled radiology trainees from Saudi Arabia, and an online 5-part-structured questionnaire was disseminated via online networks to trainees in July 2021. We included 98 participants (51 male; age $27.59 \pm 2.02$ years). Level of use was low; few used it in routine practice (7\%). The impact of artificial intelligence on the radiology workflow was positively perceived in all radiology workflow steps (range, 3.64-3.97 out of 5). A positive impact on the radiology profession was more frequently perceived for technical and performance aspects $(81 \%-85 \%)$ compared with prestige and legal aspects $(64 \%-71 \%)$. Perceived ease of use and behavioral intention to use artificial intelligence were associated with the current professional activity, level of artificial intelligence use, and perceived impact on the profession and on the radiology workflow $(\mathrm{p}<0.05)$. In summary, artificial intelligence is used at a very low level in radiology. The perceived positive impact of artificial intelligence on radiology workflow and the profession is correlated to an increase in behavioral intention to use artificial intelligence. Thus, increasing awareness about the positive impact of artificial intelligence can improve its adoption.
\end{abstract}

Keywords: Artificial intelligence; Diagnostic imaging; Education; Radiology; Saudi Arabia

\section{Introduction}

Artificial intelligence (AI) represents a revolution in data science and information technology because it improves automation tasking technology. The principle of AI and deep learning (DL), which is the most fascinating branch of AI, lies in big data processing and translating it into decision-making and in executive functions using algorithms that 
enable continuous efficiency and accuracy improvements to the operations as a function of time and usage. It is like an artificial brain that is continuously learning while integrating the infinite feedback from all the connected and engaged users, and thus, ultimately mimicking the efficiency and robustness of the human brain [1,2].

Many industries and domains are gradually becoming involved in AI and DL. In the healthcare industry, AI and DL are used on many levels including for diagnostics, therapeutic and surgical assistance, and record-keeping. The abundant biomedical data, which is generated worldwide in complex and various forms - such as electronic records, imaging files, sensor data, and texts - represents a valuable resource that AI and DL can use to assist in making accurate and highly personalized medical decisions [3-5].

Medical imaging is a specialty that has likely benefited greatly from recent AI-based innovations and advances. Computer vision and image recognition, which are two remarkable functions of AI and DL, are providing valuable input into bio-signal analysis, which is reflected in several applications in diagnostic radiology; these applications improve the speed, accuracy, and quality of their contribution to medical imaging in patient care and public health. Automated image interpretation, incidental finding detection, and optimizing workflow by flagging abnormal exams quickly in high-workflow settings are among these valuable applications. AI can also assist physicians in choosing the appropriate imaging examination and formulating a final diagnosis. Additionally, medical imaging has also used generic AI applications such as in patient scheduling or to predict wait times or appointment delays [6-10]

Several surveys have been conducted to examine radiology practitioners' perceptions and use of AI technology [10-17]. Many clinicians agreed that AI has a positive impact on their profession. A survey of trainees of the Royal College of Physicians and Surgeons in Canada showed that $72 \%$ of respondents perceived AI as having a positive impact on workflow and/or clinical practice and patient experience [18]. However, AI has not been widely adopted in the radiology field. In the United States, as many as 38\% of radiology trainees use AI in their practice [19]. In addition to the growing interest in, and applications of, AI in medical imaging, anxiety is increasing among radiologists about the potentially disrupting effect on radiology practice. Some people predict that AI will put medical imagebased professions, such as radiologists and pathologists, out of business in less than 10 years [20].

In Saudi Arabia, the level of knowledge, experience, and use of AI and DL have investigated among radiologists. However, most studies lack a reliable tool for measuring broader dimensions of the level of AI use and the perceived impact on the workflow and the radiology profession. In the present study, we aimed at assessing the levels of exposure to AI radiology, including familiarity, experience, and level of current use. We also aimed to explore the perceived contributions of AI radiology in the workflow and radiology profession. Further, we assessed the levels of perceived ease of use (PEoU) and behavioral intention (BI) toward $\mathrm{AI}$ radiology use in routine practice and to explore their predictive factors.

\section{Materials and Methods}

This cross-sectional study was performed in Saudi Arabia among all radiology residency trainees (R1s to R4s). The study commenced after obtaining ethics approval from the scientific research centre at the health services department of the Armed Forces Hospital in Taif, Saudi Arabia (Approval Ref: 2021-06-577). Participation was voluntary and anonymous. Convenience sampling was used, and a structured questionnaire was 
designed by the author, which was aided by a targeted literature search. The questionnaire comprised five parts, which are described below.

Part A- collected participants' demographic and professional data such as age, gender, sector (Ministry of Health, University, Private, etc.), and academic degree.

Part B- assessed the exposure to AI radiology using three subscales: 1) self-assessed knowledge level about AI, ML, DL, data science, and AI radiology (five items); 2) levels of involvement and interest in AI radiology (four items); and 3) current level of use (LoU) of AI radiology (Appendix A) using an adaptation of the LoU dimension scale from the Concerns-based Adoption Model (CBAM), which evaluates human factors that may interfere with successful implementation of an innovation [21]. The LoU was designed as an eight-level scale ranging from level 0 (no experience and no significant knowledge or active interest in being involved) to level 6 (engaged use with critical view regarding the functionality and improvement possibilities of the system).

Part C- explored perceptions about AI opportunities and applications in radiology, using a five-point Likert-type scale that measured the perceived level of impact (from 1 [no impact] to 5 [drastic impact]) on ten dimensions of the standard radiology workflow (Appendix B). Items in this part were developed with the six-step standard workflow in radiology, which includes ordering and scheduling, protocoling and acquisition, image interpretation, reporting, communication, and billing [6].

Part D- explored attitudes regarding the impact of AI radiology on the radiology profession. A five-point Likert-type scale was developed to measure the perspective impact of AI radiology implementation on ten dimensions of the radiology profession such as ethics, income, job opportunities, and role in society (Appendix C).

Part E- explored the PEoU and BI for AI radiology use (Appendix D) using a six-item scale (three items for PEoU and three items for BI) that was developed based on the Technology Acceptance Model (TAM) by Davis, Bagozzi, and Warshaw (1989), which originally aimed to provide an explicative and predictive model of people's readiness for and willingness to adopt a novel technology $[22,23]$.

The questionnaire was validated by assessing the face and content validity of Parts B-E and by analyzing the internal consistency of all the Likert-type scales. The questionnaire was edited for online use on Google Forms. The link was disseminated via social media to trainees' groups and networks. The survey link was kept open for 21 days in July 2021, during which several reminders were sent to prompt participation.

Scores were calculated to reflect the study outcomes including knowledge level, practice level, LoU, level of perceived impact on standard radiology workflow, perceived impact on radiologist profession, PEoU, and BI. The concerned variables were analyzed as numerical or categorical variables depending on their linearity and distribution. Statistical analysis was performed using SPSS version 21.0 for Windows (SPSS Inc., Chicago, IL, USA). Categorical variables were presented as the frequency and percentage, while numerical variables were presented as the mean \pm standard deviation (SD). Inferential analysis was performed to analyze the different associations that were stated in the objectives using appropriate tests. Where applicable, continuous data were compared using independent t-test or one-way analysis of variance (ANOVA). The correlation between scores was determined using linear regression and Person's correlation. Independent factors for PEoU and BI were assessed using stepwise linear regression with entry p-value of 0.05 and removal $\mathrm{p}$-value of 0.10 for variable selection. A $p$-value of $<0.05$ was considered to represent statistical significance.

\section{Results}

\subsection{Participant characteristics}


We included 98 radiology trainees; 51 of them were male, and their mean (SD) age was 27.59 (2.02) years. Makkah Province was predominantly represented (57\% of the participants). For professional characteristics, most participants had a bachelor's degree $(96 \%)$ and were working at an institution that was affiliated with the Ministry of Health (79\%). Additionally, 61\% had a mixed academic/non-academic job (Table 1).

Table 1. Participants' demographic and professional characteristics $(\mathrm{N}=98)$

\begin{tabular}{llcc}
\hline Parameter & Unit & Mean & SD \\
\hline Age & years & 27.59 & 2.02 \\
\hline Parameter & Category & Frequency & Percentage \\
\hline Gender & Male & 51 & 52.04 \\
& Female & 47 & 47.96 \\
\hline Province & Makkah & 55 & 56.70 \\
& Riyadh & 17.53 \\
& Eastern Province & 16.49 \\
& Madinah & 16 & 4.12 \\
& Jizan & 4 & 3.09 \\
& Aseer & 3 & 2.06 \\
\hline Sector & Ministry of Health & 2 & 78.57 \\
& University & 77 & 7.14 \\
& Military & 7 & 9.18 \\
& Other & 9 & 5.10 \\
\hline Academic degree & Bachelor's & 5 & 95.92 \\
& Masters or PhD & 94 & 4.08 \\
\hline Current professional activity & Academic & 4 & 10.20 \\
& Non-academic & 10 & 28.57 \\
\hline
\end{tabular}

SD: standard deviation

\subsection{Exposure to and interest in artificial intelligence in radiology}

Overall, $45 \%$ of the participants indicated that they were familiar with AI radiology, and among them, only two had accurate knowledge about it. Comparable levels of familiarity were observed for the other concepts including machine learning, DL, and data science. However, a minority of participants indicated that they were not involved and not interested in reading articles (14\%) or attending courses (15\%) related to AI radiology; most of the remaining participants were either interested $(47 \%-60 \%)$ or actually involved $(25 \%-39 \%)$ in such activities (Table 2). Levels of use of AI/DL radiology were very low, with 39\% having no experience or significant knowledge and a few had just started (8\%) or were using it in their routine practice (7\%) (Figure 1). 
Table 2. Exposure to and interest in artificial intelligence in radiology

\begin{tabular}{|c|c|c|c|c|c|}
\hline Scale / Item & \multicolumn{5}{|c|}{ Levels, n (N=98) } \\
\hline Familiarity & $\begin{array}{c}1 \circ \text { Never } \\
\text { heard } \\
\text { about it }\end{array}$ & $\begin{array}{l}2 \circ \text { Heard } \\
\text { about it but } \\
\text { not familiar } \\
\text { with what it } \\
\text { stands for }\end{array}$ & $\begin{array}{c}3 \circ \text { Heard } \\
\text { about it but } \\
\text { barely } \\
\text { understand } \\
\text { what it is }\end{array}$ & $\begin{array}{c}4 \circ \text { Familiar } \\
\text { with its } \\
\text { basics }\end{array}$ & $\begin{array}{c}5 \text { o Have } \\
\text { accurate } \\
\text { knowledge } \\
\text { about it }\end{array}$ \\
\hline Al radiology & 8 & 15 & 31 & 42 & 2 \\
\hline $\mathrm{ML}$ & 16 & 15 & 29 & 36 & 2 \\
\hline $\mathrm{DL}$ & 19 & 19 & 25 & 33 & 2 \\
\hline Data science & 16 & 17 & 25 & 38 & 2 \\
\hline Involvement & \multicolumn{2}{|c|}{$\begin{array}{l}1 \circ \text { No, and not } \\
\text { interested }\end{array}$} & No, but inter & sted & $3 \circ$ Yes \\
\hline $\begin{array}{l}\text { Reading journal articles about } \mathrm{Al} / \mathrm{DL} \\
\text { radiology }\end{array}$ & \multicolumn{2}{|c|}{14} & 46 & & 38 \\
\hline Attending $\mathrm{Al} / \mathrm{DL}$ radiology courses & \multicolumn{2}{|c|}{15} & 59 & & 24 \\
\hline
\end{tabular}

AI: artificial intelligence; ML: machine learning; DL: deep learning

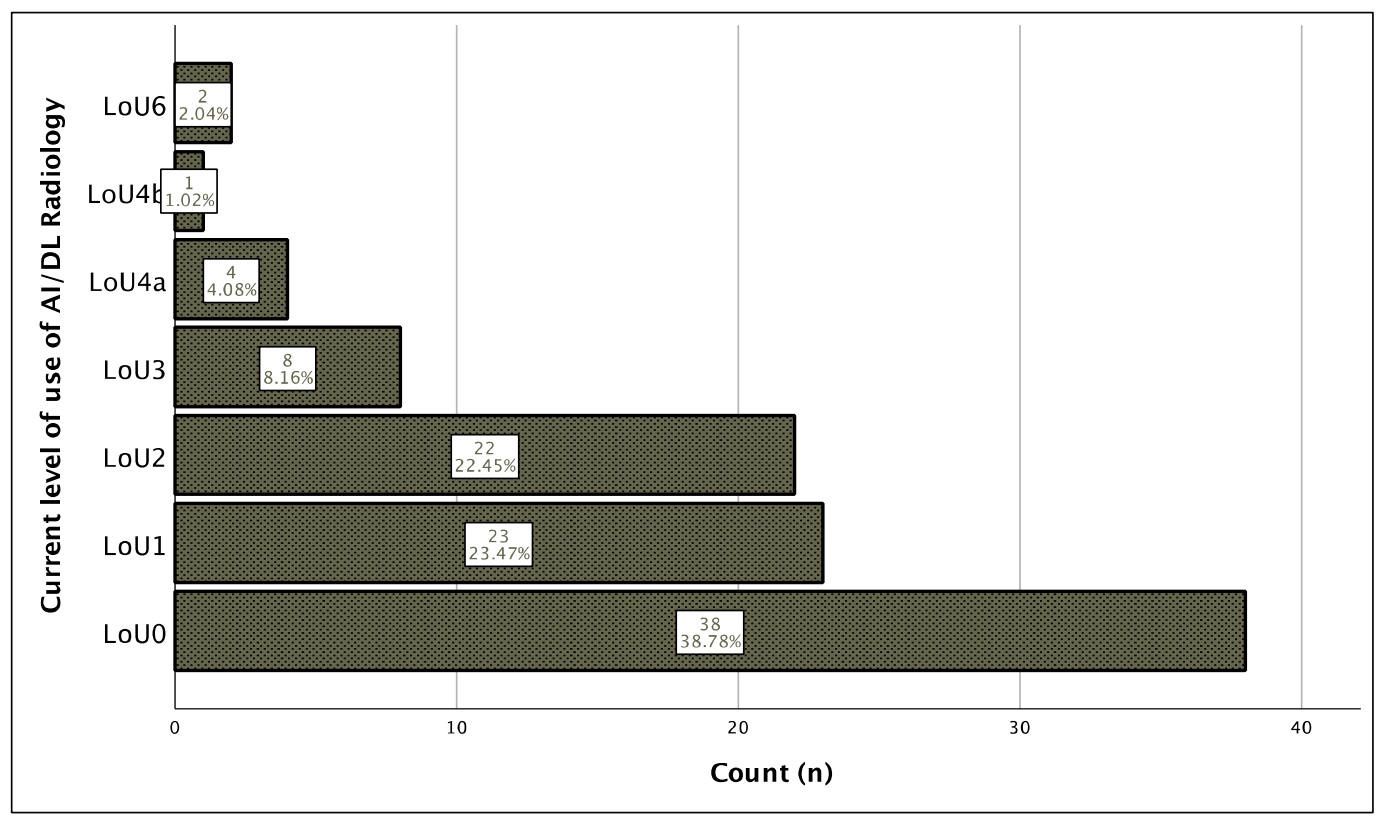

Figure 1. Levels of use of AI/DL radiology. LoU: Level of use.

\subsection{Perceived impact of AI radiology on radiology workflow and the radiology profession}

Overall, the impact of AI radiology on radiology workflow was perceived to be high throughout the steps of radiology workflow, and the most highly perceived impact was in the enhancement of image acquisition (mean score, 3.97 out of 5), enabling automated protocol selection (3.94 out of 5), and optimization of patient scheduling and resources (3.93 out of 5) (Figure 2). For the perceived impact on the radiology profession, a positive impact was most frequently perceived in technical and logistic aspects such as image 
interpretation (85\%), image quality acquisition ( $85 \%)$, workload $(82 \%)$, and wait times and appointment delay $(81 \%)$, whereas the perceived impact was relatively less positive in aspects related to prestige and regulation such as the radiologist's role in society $(71 \%)$, medical liability $(70 \%)$, income $(65 \%)$, and ethics $(64 \%)$ (Figure 3 )

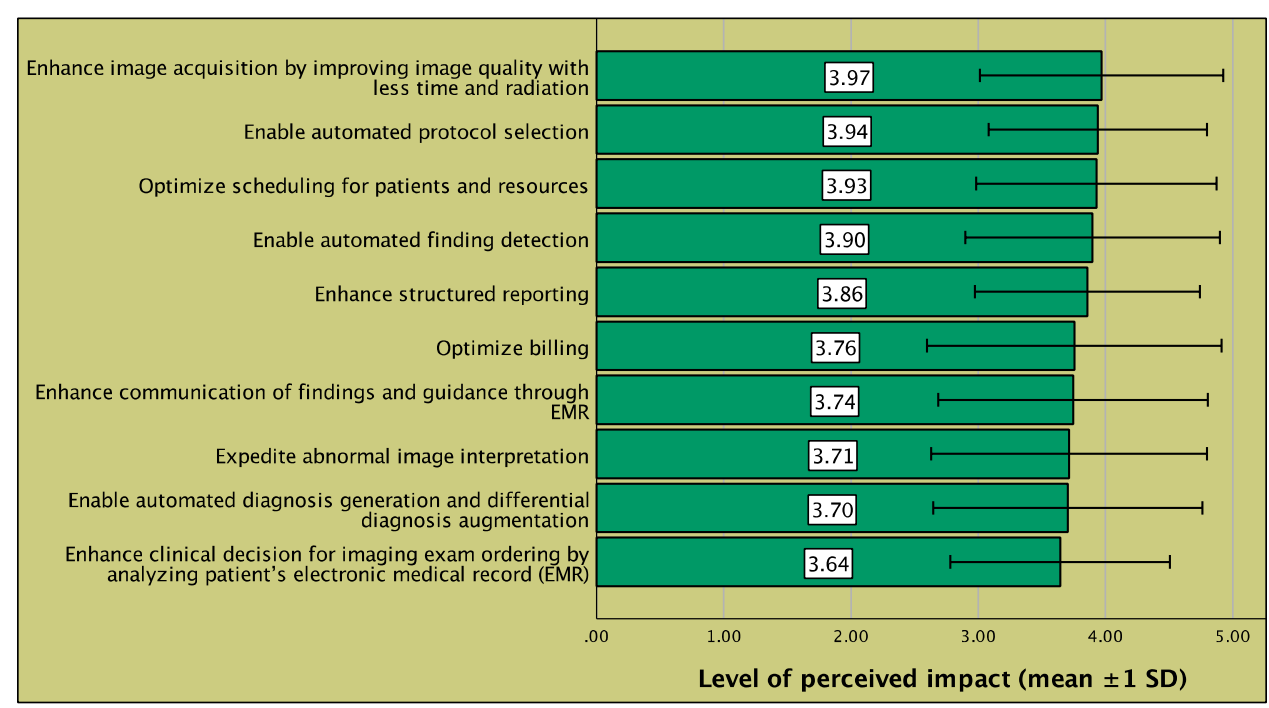

Figure 2. Perceived impact of $A I, M L$, and DL on the different steps of standard radiology workflow. Bars represent the mean level of perceived impact, on a scale of 1 to $5(1$, no impact; 5, drastic impact) for AL, ML, and DL on the given step of standard radiology workflow. EMR: electronic medical record; SD: standard deviation.

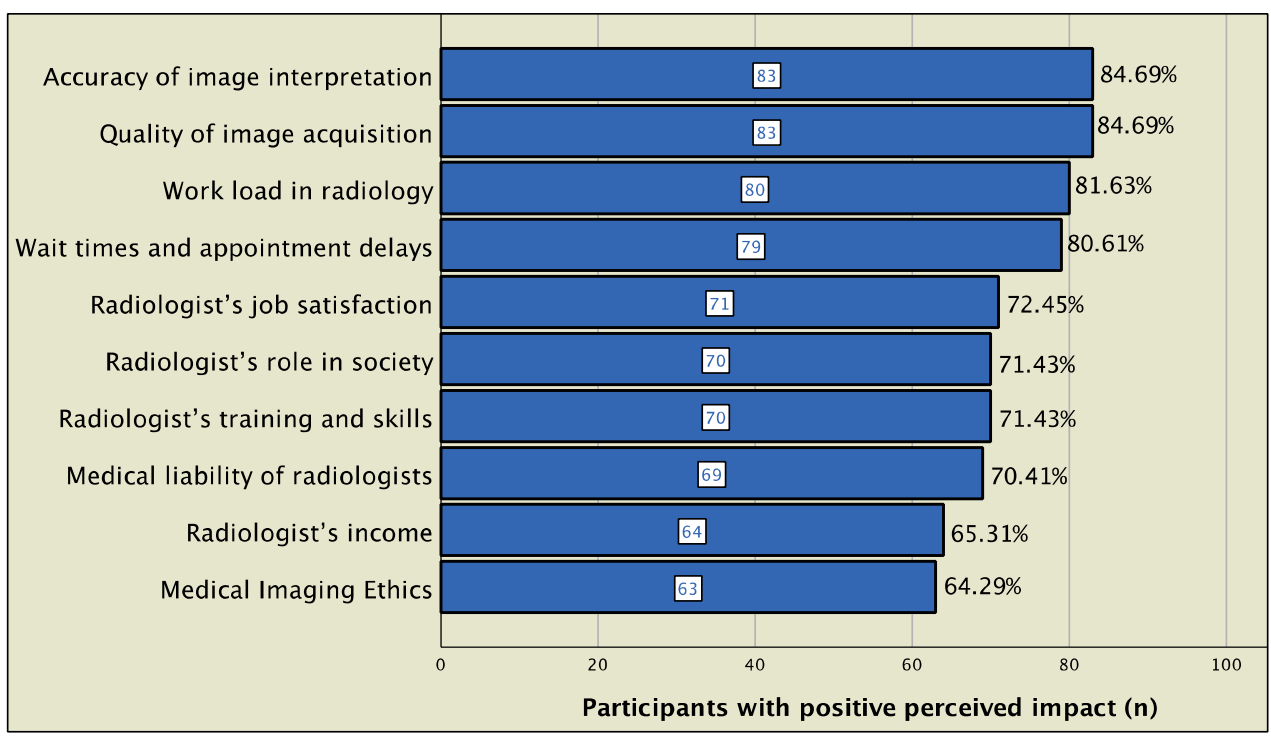

Figure 3. Attitudes regarding AI radiology impact on the radiology profession. Bars represent the percentage of participants who perceived the impact of AI radiology as being positive or very positive on the given aspect of the radiology profession. Participants responded to the question: "In your opinion, how would the implementation of AI radiology impact each of the following aspects of the radiology profession?" 


\subsection{Internal consistency of the study scales}

All four study scales used in the present study showed high or very high reliability, including perceived impact of AI radiology on radiology workflow (Cronbach's alpha, 0.955), perceived impact of AI radiology on the radiology profession (0.926), PEoU of AI radiology (0.883), and BI to use AI radiology (0.888) (Table 3). Consequently, scores were calculated for each scale, and the respective means and ranges are presented in Table 3 with a comparison to the reference ranges.

Table 3. Internal consistency of the four study scales

\begin{tabular}{|c|c|c|c|c|c|c|c|}
\hline \multirow[b]{2}{*}{ Scale } & \multirow{2}{*}{$\begin{array}{l}\text { No. } \\
\text { items }\end{array}$} & \multirow{2}{*}{$\begin{array}{c}\text { Cronbach's } \\
\text { alpha }\end{array}$} & \multirow{2}{*}{$\begin{array}{c}\text { Internal } \\
\text { consistency } \\
\text { level } \\
\end{array}$} & \multicolumn{3}{|c|}{ Score statistics } & \multirow{2}{*}{$\begin{array}{c}\text { Ref. scale } \\
\text { range }\end{array}$} \\
\hline & & & & Mean & SD & Range & \\
\hline $\begin{array}{ll}\text { Opinions about } & \text { AI } \\
\text { opportunities } & \text { in } \\
\text { radiology } & \\
\end{array}$ & 10 & 0.955 & Very high & 38.15 & 8.37 & 10,50 & 10,50 \\
\hline $\begin{array}{l}\text { Attitudes regarding AI } \\
\text { Radiology impact on the } \\
\text { radiology profession }\end{array}$ & 10 & 0.926 & Very high & 9.37 & 7.39 & $-9,20$ & $-20,+20$ \\
\hline Perceived ease of use & 3 & 0.883 & High & 11.88 & 2.00 & 9,15 & 3,15 \\
\hline Behavioural intention & 3 & 0.888 & High & 12.21 & 2.00 & 8,15 & 3,15 \\
\hline
\end{tabular}

AI: artificial intelligence; SD: standard deviation.

3.5. Factors associated with perceived impact of AI radiology on standard radiology workflow and on the radiology profession

Younger participants (age $<28$ years) had a higher perceived impact on both radiology workflow (mean \pm SD score, $39.83 \pm 8.00$ versus $35.14 \pm 8.29, \mathrm{p}=0.007$ ) and profession (mean \pm SD score, $11.22 \pm 5.95$ versus $6.03 \pm 8.57, \mathrm{p}<0.001$ ) compared to those aged 28 years and older. Participants with a postgraduate degree (Masters or $\mathrm{PhD}$ ) also had a higher perceived impact of AI radiology on both radiology workflow (mean \pm SD score, $46.25 \pm 6.18$ versus $37.81 \pm 8.30, \mathrm{p}=0.048$ ) and profession (mean \pm SD score, $16.25 \pm 7.50$ versus $9.07 \pm 7.28$, $\mathrm{p}=0.028)$, compared to those with a bachelor's degree alone. Additionally, trainees with mixed academic/non-academic job activity had a higher perceived impact of AI radiology on both the radiology workflow (mean \pm SD score, 41.90 \pm 5.31 versus $27.40 \pm 9.11$ and $33.96 \pm 8.38, \mathrm{p}<0.001$ ) and profession (mean $\pm \mathrm{SD}, 13.27 \pm 4.41$ versus $1.50 \pm 2.88$ and $3.82 \pm 7.89$, $\mathrm{p}<0.001)$ compared with those who had an exclusively academic or non-academic job activity. (Table 4). 
Table 4. Factors associated with perceived impact of AI on standard radiology workflow and on the radiology profession

\begin{tabular}{|c|c|c|c|c|c|c|c|}
\hline \multirow[t]{2}{*}{ Parameter } & \multirow[t]{2}{*}{ Unit } & \multicolumn{3}{|c|}{$\begin{array}{c}\text { Perceived impact on } \\
\text { standard radiology } \\
\text { workflow }\end{array}$} & \multicolumn{3}{|c|}{$\begin{array}{l}\text { Perceived impact on the } \\
\text { radiology profession }\end{array}$} \\
\hline & & Mean & SD & $\begin{array}{c}\mathrm{p}- \\
\text { value }\end{array}$ & Mean & SD & $\mathrm{p}$-value \\
\hline \multirow[t]{2}{*}{ Age } & $<28$ years & 39.83 & 8.00 & & 11.22 & 5.95 & \\
\hline & $\geq 28$ years & 35.14 & 8.29 & $.007^{*}$ & 6.03 & 8.57 & $<.001^{*}$ \\
\hline \multirow[t]{2}{*}{ Gender } & Male & 38.55 & 6.58 & & 9.02 & 6.60 & \\
\hline & Female & 37.72 & 10.01 & .628 & 9.74 & 8.21 & .630 \\
\hline \multirow[t]{6}{*}{ Province } & Makkah & 38.51 & 8.87 & & 10.11 & 7.47 & \\
\hline & Riyadh & 38.59 & 6.39 & & 9.94 & 7.89 & \\
\hline & Eastern Province & 35.44 & 8.97 & & 6.19 & 7.73 & \\
\hline & Madinah & 40.75 & 1.50 & & 10.75 & 4.65 & \\
\hline & Jizan & 34.67 & 12.86 & & 8.67 & 7.09 & \\
\hline & Aseer & 47.00 & 0.00 & .433 & 10.00 & 0.00 & .592 \\
\hline \multirow[t]{4}{*}{ Sector } & Ministry of Health & 39.30 & 6.98 & & 10.05 & 7.29 & \\
\hline & University & 33.43 & 13.05 & & 4.71 & 6.50 & \\
\hline & Military & 32.89 & 12.44 & & 9.00 & 7.98 & \\
\hline & Other & 36.60 & 8.91 & .057 & 6.00 & 7.97 & .214 \\
\hline \multirow[t]{2}{*}{ Academic degree } & Bachelor's & 37.81 & 8.30 & & 9.07 & 7.28 & \\
\hline & Masters or PhD & 46.25 & 6.18 & $.048^{*}$ & 16.25 & 7.50 & $.028 *$ \\
\hline \multirow{3}{*}{$\begin{array}{l}\text { Current } \\
\text { professional } \\
\text { activity }\end{array}$} & Academic & 27.40 & 9.11 & & 1.50 & 2.88 & \\
\hline & Non-academic & 33.96 & 8.38 & & 3.82 & 7.89 & \\
\hline & Mixed & 41.90 & 5.31 & $<.001^{*}$ & 13.27 & 4.41 & $<.001^{*}$ \\
\hline
\end{tabular}

SD: standard deviation. *Statistically significant result $(\mathrm{p}<0.05)$.

\subsection{Factors associated with perceived ease of use of AI radiology}

The PEoU of AI radiology score was higher among younger participants $(\mathrm{p}<0.001)$ and those with mixed academic/non-academic activity ( $<<0.001)$. Additionally, the PEoU score was positively correlated with the LoU of AI radiology (unstandardized regression coefficient $\mathrm{B}=0.40, \mathrm{R}=0.41, \mathrm{p}<0.001$ ), perceived impact on workflow $(\mathrm{B}=0.10, \mathrm{R}=0.62$, $p<0.001)$, and perceived impact on the radiology profession $(B=0.14, R=0.70, p<0.001)$ (Table 5). Among these significant factors, current professional activity $(B=0.55, p=0.005)$, LoU $(\mathrm{B}=0.15, \mathrm{p}=0.043)$, and perceived impact on profession score $(\mathrm{B}=0.09, \mathrm{p}<0.001)$ were independently associated with the PEoU of AI radiology in a multivariate model that explained $55.7 \%$ of the variance in the PEoU of AI radiology score (Table 6).

\subsection{Factors associated with behavioural intention to use AI radiology}

The BI to use AI radiology score was higher among younger participants $(\mathrm{p}<0.001)$ and those having mixed academic/non-academic job activity $(\mathrm{p}<0.001)$. It was linearly correlated with the LoU of AI radiology $(B=0.50, R=0.36$, $p<0.001)$, perceived impact on workflow $(\mathrm{B}=0.18, \mathrm{R}=0.74, \mathrm{p}<0.001)$, and perceived impact on the radiology profession $(\mathrm{B}=0.22$, $\mathrm{R}=0.82$, $\mathrm{p}<0.001$ ) (Table 5). The multivariate model showed that only perceived impact on workflow $(\mathrm{B}=0.07, \mathrm{p}<0.001)$ and perceived impact on the profession $(\mathrm{B}=0.16, \mathrm{p}<0.001)$ were independent factors, which explained $71.2 \%$ of the variance in the BI score (Table 6) 
Table 5. Factors associated with perceived ease of use and behavioral intention to use AI radiology

\begin{tabular}{|c|c|c|c|c|c|c|c|c|c|}
\hline \multirow{2}{*}{ Parameter } & \multirow{2}{*}{ Unit } & \multicolumn{4}{|c|}{ Perceived ease of use } & \multicolumn{4}{|c|}{ Behavioural intention } \\
\hline & & Mean & SD & & lue & Mean & SD & \multirow{3}{*}{\multicolumn{2}{|c|}{$<.001^{*}$}} \\
\hline \multirow[t]{2}{*}{ Age } & $<28$ years & 13.16 & 1.35 & \multirow{2}{*}{\multicolumn{2}{|c|}{$<.001^{*}$}} & 12.76 & 1.64 & & \\
\hline & $\geq 28$ years & 12.17 & 1.34 & & & 11.23 & 2.22 & & \\
\hline \multirow[t]{2}{*}{ Gender } & Male & 12.78 & 1.29 & \multirow{2}{*}{\multicolumn{2}{|c|}{.875}} & 12.25 & 1.90 & \multirow{2}{*}{\multicolumn{2}{|c|}{.835}} \\
\hline & Female & 12.83 & 1.56 & & & 12.17 & 2.13 & & \\
\hline \multirow[t]{6}{*}{ Province } & Makkah & 12.78 & 1.42 & & & 12.45 & 2.04 & & \\
\hline & Riyadh & 13.06 & 1.39 & & & 12.12 & 1.96 & & \\
\hline & Eastern Province & 12.75 & 1.39 & & & 11.63 & 2.06 & & \\
\hline & Madinah & 12.50 & 2.52 & & & 12.25 & 2.06 & & \\
\hline & Jizan & 12.67 & 1.53 & & & 12.00 & 2.65 & & \\
\hline & Aseer & 13.00 & 0.00 & \multicolumn{2}{|c|}{.977} & 12.00 & 0.00 & \multicolumn{2}{|c|}{.820} \\
\hline \multirow[t]{4}{*}{ Sector } & Ministry of Health & 12.88 & 1.40 & & & 12.35 & 1.99 & & \\
\hline & University & 12.57 & 0.79 & & & 11.29 & 2.21 & & \\
\hline & Military & 12.11 & 1.96 & & & 11.78 & 2.22 & & \\
\hline & Other & 13.20 & 1.10 & \multicolumn{2}{|c|}{.402} & 12.20 & 1.64 & \multicolumn{2}{|c|}{.520} \\
\hline \multirow[t]{2}{*}{ Academic degree } & Bachelor's & 12.77 & 1.42 & \multirow{2}{*}{\multicolumn{2}{|c|}{.176}} & 12.14 & 1.98 & \multirow{2}{*}{\multicolumn{2}{|c|}{0.068}} \\
\hline & Masters or PhD & 13.75 & 1.26 & & & 14.00 & 2.00 & & \\
\hline \multirow{3}{*}{$\begin{array}{l}\text { Current } \\
\text { professional } \\
\text { activity }\end{array}$} & Academic & 11.40 & 1.51 & \multirow{3}{*}{\multicolumn{2}{|c|}{$<.001^{*}$}} & 10.10 & 1.29 & \multirow{3}{*}{\multicolumn{2}{|c|}{$<.001^{*}$}} \\
\hline & Non-academic & 11.79 & 1.17 & & & 11.18 & 2.29 & & \\
\hline & Mixed & 13.52 & 1.00 & & & 13.05 & 1.40 & & \\
\hline \multicolumn{2}{|l|}{ Score } & B & $95 \% \mathrm{CI}$ & $\mathbf{R}$ & $\begin{array}{c}\text { p- } \\
\text { value }\end{array}$ & B & $95 \% \mathrm{CI}$ & $\mathbf{R}$ & $\begin{array}{c}\text { p- } \\
\text { value }\end{array}$ \\
\hline \multicolumn{2}{|c|}{ Level of use of AI radiology } & 0.40 & $0.22,0.58$ & 0.41 & $<.001^{*}$ & 0.50 & $0.24,0.75$ & 0.36 & $<.001^{*}$ \\
\hline \multicolumn{2}{|c|}{ Perceived impact on workflow } & 0.10 & $0.08,0.13$ & 0.62 & $<.001^{*}$ & 0.18 & $0.14,0.21$ & 0.74 & $<.001^{*}$ \\
\hline \multicolumn{2}{|c|}{ Perceived impact on profession } & 0.14 & $0.11,0.16$ & 0.70 & $<.001^{*}$ & 0.22 & $0.19,0.25$ & 0.82 & $<.001^{*}$ \\
\hline
\end{tabular}

B: Unstandardised regression coefficient; 95\%CI: 95\% confidence interval; R: Pearson's correlation coefficient; AI: artificial intelligence; SD: standard deviation. *Statistically significant result $(\mathrm{p}<0.05)$ 
Table 6. Independent factors associated with perceived ease of use and behavioral intention to use $\mathrm{AI}$ radiology (stepwise linear regression)

\begin{tabular}{|c|c|c|c|c|c|c|c|c|c|c|}
\hline \multirow{3}{*}{$\begin{array}{l}\text { Parameter } \\
\text { Current } \\
\text { activity }\end{array}$} & & \multirow{3}{*}{$\begin{array}{l}\begin{array}{l}\text { No. of } \\
\text { levels }\end{array} \\
3\end{array}$} & \multicolumn{4}{|c|}{ Perceived ease of use $^{\dagger}$} & \multicolumn{4}{|c|}{ Behavioural intention $^{\ddagger}$} \\
\hline & & & B & \multicolumn{2}{|c|}{$95 \% \mathrm{CI}$} & \multirow{2}{*}{$\begin{array}{c}\text { p-value } \\
.005^{*}\end{array}$} & B & \multicolumn{2}{|c|}{$95 \% \mathrm{CI}$} & $\begin{array}{c}\text { p- } \\
\text { value }\end{array}$ \\
\hline & professional & & 0.55 & 0.17 & 0.93 & & & \multicolumn{2}{|c|}{ NI } & \\
\hline $\begin{array}{l}\text { Level of } \\
\text { radiology }\end{array}$ & use of AI & (discrete) & 0.15 & 0.01 & 0.29 & $.043^{*}$ & & \multicolumn{2}{|c|}{ NI } & \\
\hline $\begin{array}{l}\text { Perceived } \\
\text { workflow }\end{array}$ & impact on & (discrete) & \multicolumn{4}{|c|}{ NI } & 0.07 & 0.03 & 0.11 & $<.001^{*}$ \\
\hline $\begin{array}{l}\text { Perceived } \\
\text { profession }\end{array}$ & impact on & (discrete) & 0.09 & 0.06 & 0.13 & $<.001^{*}$ & 0.16 & 0.12 & 0.21 & $<.001^{*}$ \\
\hline \multicolumn{3}{|c|}{ Model goodness-of-fit $\left(\mathrm{R}^{2}\right)$} & \multicolumn{4}{|c|}{0.557} & \multicolumn{4}{|c|}{0.712} \\
\hline
\end{tabular}

AI: artificial intelligence; NI: variable not included in the model; B: Linear regression coefficient; 95\%CI: 95\% confidence interval; R2: squared Pearson's correlation coefficient. *Statistically significant result $(\mathrm{p}<0.05){ }^{\dagger}$ Factors removed from the model in the stepwise approach: age, gender, province, sector, academic degree, and perceived impact on workflow. model in the stepwise approach: age, gender, province, sector, academic degree, current professional activity, and level of use of AI radiology.

\section{Discussion}

AI and DL are breakthroughs that have dramatically transformed health care, particularly, medical imaging. However, opinions and attitudes of health professionals may be divided between enthusiasm for its contributions to medical imaging and concerns about changing the radiology profession. In this cross-sectional study, the author developed a five-part structured reliable questionnaire to assess the level of exposure to AI radiology among radiology trainees in Saudi Arabia, as well as their perspectives on its contributions to enhancing medical imaging and the eventual multidimensional impact on the radiology profession. This study also assessed the PEoU and BI levels as a predictive model of the trainees' readiness for and willingness to adopt AI radiology.

Familiarity with $\mathrm{AI}$ in radiology has been reported in regional studies. According to a recent study from Saudi Arabia, most radiology trainees are unfamiliar with AI [23]. In our study, the radiology trainees were inadequately exposed to AI/DL technologies. They had a limited knowledge of AI radiology. We expanded on regional published findings and revealed comparable levels of familiarity with the other concepts including machine learning, DL, and data science. Upon further inquiry, we discovered that the majority of our participants were interested in or had already been involved in academic activities related to AI, despite it being recently introduced in this field. Another study from Singapore explored the level of familiarity, as well as the interest and opinions of 125 radiologists from different diagnostic and interventional subspecialties. Among the participants, $15.2 \%$ considered themselves competent in AI for medical imaging, $16.8 \%$ were actively involved in AI radiology research, and $19.2 \%$ had attended AI and data science courses within the last 5 years [15]. Abuzaid et al. argued that radiographers in Saudi Arabia face challenges in acquiring AI-related education and training, and they reported that there is a lack of education courses to facilitate AI use [16]. 
The use of AI in radiology is suboptimal. A regional study reported that as many as $82 \%$ of the radiology professionals had never used AI in their practice. However, the majority of respondents expressed an interest in incorporating AI into radiology practice [12]. A study from the United States assessed 95 thoracic radiologists' perceptions about the role and expected impact of AI in radiology and compared their perspectives with those of 45 computer scientists. Although all radiologists declared having heard about AI or read related scientific articles, only $23.2 \%$ indicated that they used it, compared to $91.1 \%$ of computer scientists [11]. Similarly, in our study, the minority used AI in their clinical practice. Further, our study showed that low levels of knowledge and use of AI were associated with a low PEoU and BI to use AI. Therefore, levels of knowledge, exposure, and practice in AI radiology among radiology trainees should be increased to alleviate misconceptions and to enhance the BI to use it.

The workflow and workload of radiology has been increasing, making it challenging to report an overwhelming number of cases in a timely manner [24]. The impact of AI on radiology workflow has been viewed positively in a large number of studies. In our survey, the impact of AI on radiology workflow was widely viewed favorably throughout the radiology workflow steps. Opinions were more positive among the young generation of trainees and those having mixed academic/non-academic work experience. The most highly perceived positive impact was in the enhancement of image acquisition in a timely manner. A group of researchers from Saudi Arabia believed that AI reduces the workload in radiology [23]. Furthermore, trainees from Australia and New Zealand indicated that the top benefit of AI is to reduce time spent by specialists on monotonous tasks [25]. An internet-based national study from Italy explored perceptions among 1,032 radiologists about different usage, advantages, and potential issues of AI in medical imaging as a result of AI radiology implementation. Two-thirds of respondents viewed AI as an aid to daily working practice, mainly in image interpretation, and they had an overall positive attitude regarding its impact on improving the accuracy and turnaround time in radiology [17]. Additionally, we found that AI was expected to enable the automated protocol selection and to improve the automated radiological findings detection. Similarly, Qurashi et al. found that the majority of their participants agreed that AI is a useful tool in automated imaging protocol selection, that is beneficial in improving timely diagnosis, and can assist in personalizing imaging for patients, such as tracking radiation dose and follow-up examinations [12]. Our study revealed that the positive perceived impact on radiology workflow is correlated with BI to use AI. Thus, raising awareness about the positive impact of AI on radiology workflow will contribute to improve the levels of behavioral use.

The advent of AI in radiology and its implications have elicited a variety of perspectives about the future of the radiology profession. The impact of AI use on the radiology profession is being debated. In a study conducted in the United States, none of the attending radiologists and only a very small proportion of the trainees believed that their jobs would be obsolete in the next 10-20 years [19]. Surprisingly, a study reported that more than a half of Saudi radiology personnel are concerned about the negative impact of AI on their profession [12]. Some claimed that AI implementation can potentially reduce staffing levels and would integrate their roles [26]. Others claimed that $60 \%$ were concerned about AI disruption of the radiologist's professional reputation, while less than $20 \%$ were concerned about radiologists' income and recruitment opportunities decreasing as a result of AI radiology implementation [17]. Conversely, another Saudi survey demonstrated that a majority of the radiologists did not believe that AI is a threat [14]. In our study, we found that only 19\% were concerned about job appointment delays, and 35\% negatively perceived the impact of AI on their income. Furthermore, approximately 30\% of the participants were concerned about medical liability and ethical consequences to AI implementation. Opinions, overall, were more positive among younger participants and those with a higher degree, as well as among those with mixed work experience. The positively perceived impact on the profession was a determining factor in increasing the level 
of both PEoU and BI to use AI. There is a need to alleviate misconceptions about the impact of AI radiology on the radiology profession to enhance BI.

It has been expected that AI would drastically revolutionize radiology in the next years [15]. In particular, it was believed that it would be 5 years or less before AI had a noticeable impact on the profession [25]. Although some showed excitement for the change in the next years, only $12.0 \%$ suggested that it would replace human competency [15]. The influence of AI on the radiologist's job was expected to be dramatic by $5.3 \%$ compared to $11.1 \%, 32.7 \%$ compared to $60.0 \%$, and $64.3 \%$ compared to $88.9 \%$ of radiologists compared to computer scientists in the next 5,10 , and 20 years, respectively [11]. Few radiologists suggested that the implementation of $\mathrm{AI}$ in radiology would negatively impact the radiologists' job satisfaction (49.5\%) and role in society (11.6\%) [11]. Some radiology practitioners are highly concerned that AI will result in healthcare being divested to large technology and data companies [25].

The authors approached the study participants using a convenience sampling method. Thus, the results may not be generalizable. Additionally, the response rate and sample size were low resulting in low statistical power.

\section{Conclusion}

Levels of use of AI/DL in radiology are very low, despite the relatively high familiarity among the trainees. AI is perceived to have a positive impact on the enhancement of image acquisition, image interpretation, image quality acquisition, and workload. The perceived ease of use of AI and the estimated behavioral intention to use AI are influenced by the level of AI use and the perceived impact of AI on the workflow and the profession. Therefore, the levels of exposure and practice in AI radiology among Saudi radiology trainees should be further enhanced and misconceptions should be addressed to enable efficient implementation and use of this new technology.

Supplementary Materials: Appendix A: Level of use of Artificial Intelligence/Deep Learning Radiology; Appendix B: Opinions about the opportunities of artificial intelligence in radiology; Appendix C: Attitudes regarding AI Radiology impact on the Radiologist Profession; Appendix D: Perceived ease of use (PEoU) and behavioral intention (BI) of AI radiology use in routine practice

Author Contributions: Conceptualization, Omar M. Wazgar and Yahea A. Alzahrani; Data curation, Mohammed A. Alsakkaf; Formal analysis, Ahmad A. Mirza; Investigation, Ammar A. Almaghrabi, Roaa M. Ghandour and Sarah A. Alenizi; Methodology, Abdulrahim A. Mirza; Writing original draft, Ahmad A. Mirza, Omar M. Wazgar, Ammar A. Almaghrabi, Roaa M. Ghandour, Sarah A. Alenizi, Khalid S. Alraddadi, Abdulrahim A. Mirza and Fayzah H. Al-Adwani; Writing review \& editing, Khalid S. Alraddadi, Fayzah H. Al-Adwani, Mohammed A. Alsakkaf and Yahea A. Alzahrani.

Funding: This research received no external funding.

Institutional Review Board Statement: The study was conducted in accordance with the Declaration of Helsinki and approved by the Ethics Committee of the Scientific Research Center at the Health Services Department of Armed Forces Hospital in Taif, Saudi Arabia (Approval Ref: 2021-06577, date of approval: 32 June 2021).

Informed Consent Statement: Informed consent was obtained from all subjects involved in the study

Data Availability Statement: Data generated during the study are available upon reasonable request. 
Acknowledgments: The authors sincerely acknowledge Dr. Mohamed A. HAIRECHE for his support in language editing.

Conflicts of Interest: The authors declare no conflict of interest.

Appendix A: Level of use of Artificial Intelligence/Deep Learning Radiology

\begin{tabular}{|c|c|}
\hline LoUO & $\begin{array}{l}\text { I have no experience in AI/DL Radiology; I have no significant knowledge about it and I } \\
\text { am doing nothing towards becoming involved in it }\end{array}$ \\
\hline LoU1 & $\begin{array}{l}\text { I have acquired or am acquiring information about Al/DL Radiology; I am exploring its } \\
\text { value and its demands upon physicians and health institutions }\end{array}$ \\
\hline LoU2 & I think I am ready for AI/DL Radiology implementation and am preparing for my first use \\
\hline LoU3 & $\begin{array}{l}\text { I have already made my first steps in Al/DL Radiology; I am using it superficially or } \\
\text { whenever I need it }\end{array}$ \\
\hline LoU4a & $\begin{array}{l}\text { I am using Al/DL Radiology in my routine practice but I have no idea about its impact on } \\
\text { my patients or the quality of care }\end{array}$ \\
\hline LoU4b & $\begin{array}{l}\text { I am using Al/DL Radiology and attempting to optimize my use to meet my patients' needs } \\
\text { and or improve my clinical practice }\end{array}$ \\
\hline LoU5 & $\begin{array}{l}\text { I am using Al/DL Radiology and coordinating my efforts with other colleagues and health } \\
\text { professionals for best effect on patient care }\end{array}$ \\
\hline LoU6 & $\begin{array}{l}\text { I am using Al/DL Radiology and I think there are some necessary modifications to the } \\
\text { system to achieve increased impact of patients; } \\
\text { Or, } \\
\text { I am using Al/DL Radiology and I think its scope should be expanded to new goals }\end{array}$ \\
\hline
\end{tabular}

Appendix B: Opinions about the opportunities of artificial intelligence in radiology

\begin{tabular}{|c|c|c|c|c|c|c|c|}
\hline $1 \circ$ No impact & $2 \circ$ Small impact & $\begin{array}{l}3 \circ \text { Moderate } \\
\text { impact }\end{array}$ & \multicolumn{2}{|c|}{4 ○ Large impact } & \multicolumn{3}{|c|}{5 - Drastic impac } \\
\hline 01 & $\begin{array}{l}\text { Enhance clinical decision fo } \\
\text { analyzing patient's electron }\end{array}$ & $\begin{array}{l}\text { imaging exam ordering by } \\
\text { medical record (EMR) }\end{array}$ & 10 & $2 \circ$ & $3 \circ$ & $4 \circ$ & $5 \circ$ \\
\hline 02 & Optimize scheduling for pati & nts and resources & 10 & $2 \circ$ & $3 \circ$ & $4 \circ$ & $5 \circ$ \\
\hline 03 & Enable automated protocol & election & 10 & $2 \circ$ & $3 \circ$ & $4 \circ$ & $5 \circ$ \\
\hline 04 & $\begin{array}{l}\text { Enhance image acquisition } \\
\text { with less time and radiation }\end{array}$ & y improving image quality & 10 & $2 \circ$ & $3 \circ$ & $4 \circ$ & $5 \circ$ \\
\hline 05 & Enable automated finding o & tection & 10 & $2 \circ$ & $3 \circ$ & $4 \circ$ & $5 \circ$ \\
\hline 06 & $\begin{array}{l}\text { Enable automated diagnosi } \\
\text { diagnosis augmentation }\end{array}$ & generation and differential & 10 & $2 \circ$ & $3 \circ$ & $4 \circ$ & $5 \circ$ \\
\hline 07 & Expedite abnormal image in & erpretation & 10 & $2 \circ$ & $3 \circ$ & $4 \circ$ & $5 \circ$ \\
\hline 08 & Enhance structured reportin & & 10 & $2 \circ$ & $3 \circ$ & $4 \circ$ & $5 \circ$ \\
\hline 09 & $\begin{array}{l}\text { Enhance communication of } \\
\text { through EMR }\end{array}$ & indings and guidance & 10 & $2 \circ$ & $3 \circ$ & $4 \circ$ & $5 \circ$ \\
\hline 10 & Optimize billing & & 10 & $2 \circ$ & $3 \circ$ & $4 \circ$ & $5 \circ$ \\
\hline
\end{tabular}


Appendix C: Attitudes regarding AI Radiology impact on the Radiologist Profession

How would the implementation of Al radiology impact each of the following aspects of the radiologist profession?

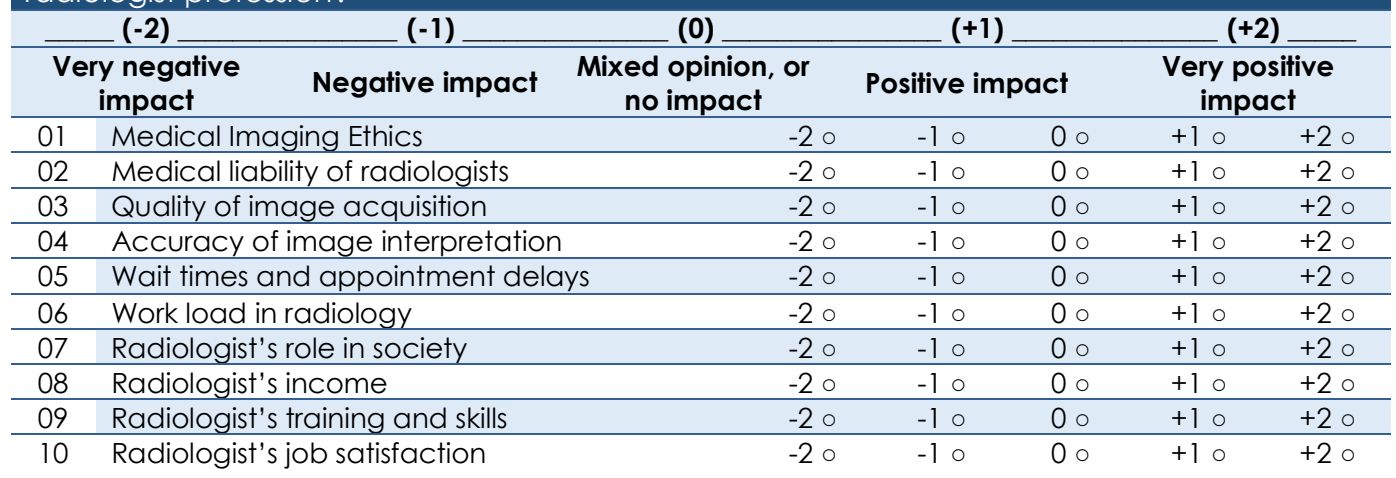

Appendix D: Perceived ease of use (PEoU) and behavioral intention (BI) of AI radiology

\begin{tabular}{|c|c|c|c|c|c|c|}
\hline se & routine & & & & ctice & \\
\hline lease & te your level of agreement to the following statements & & & & & \\
\hline Extreme & $\begin{array}{lcc}1 & 2 & 3 \\
\text { y disagree } & \text { Disagree } & \text { I do not know }\end{array}$ & & & Extre & $\begin{array}{c}5 \\
\text { iely }\end{array}$ & \\
\hline PEoU1 & $\begin{array}{l}\text { Understanding the principles of Al Radiology would be easy } \\
\text { for me }\end{array}$ & 10 & 20 & $3 \circ$ & $4 \circ$ & $5 \circ$ \\
\hline PEOU2 & Learning to operate Al Radiology would be easy for me & & & & & \\
\hline PEOU3 & $\begin{array}{l}\text { I would find it easy to do all what I need to do in my } \\
\text { practice using AI Radiology }\end{array}$ & 10 & $2 \circ$ & 30 & $4 \circ$ & $5 \circ$ \\
\hline BI1 & $\begin{array}{l}\text { Assuming I have access to the system, I intend to use } \mathbf{A l} \\
\text { Radiology }\end{array}$ & 10 & 20 & 30 & $4 \circ$ & $5 \circ$ \\
\hline B12 & $\begin{array}{l}\text { To the extent possible, I intend to use } \mathbf{A l} / \mathbf{D L} \text { technology in all } \\
\text { dimensions of my radiology practice }\end{array}$ & 10 & $2 \circ$ & $3 \circ$ & $4 \circ$ & $5 \circ$ \\
\hline BI3 & I intend to encourage my colleagues to use Al Radiology & 10 & 20 & $3 \circ$ & $4 \circ$ & $5 \circ$ \\
\hline
\end{tabular}

\section{References}

1. Arel, I.; Rose, D.C.; Karnowski, T.P. Deep machine learning-a new frontier in artificial intelligence research [research frontier]. IEEE computational intelligence magazine 2010, 5, 13-18, doi:10.1109/MCI.2010.938364.

2. Ongsulee, P. Artificial intelligence, machine learning and deep learning. In Proceedings of the 2017 15th International Conference on ICT and Knowledge Engineering (ICT\&KE), 2017; pp. 1-6.

3. Miotto, R.; Wang, F.; Wang, S.; Jiang, X.; Dudley, J.T. Deep learning for healthcare: review, opportunities and challenges. Brief Bioinform 2018, 19, 1236-1246, doi:10.1093/bib/bbx044. 
4. Esteva, A.; Robicquet, A.; Ramsundar, B.; Kuleshov, V.; DePristo, M.; Chou, K.; Cui, C.; Corrado, G.; Thrun, S.; Dean, J. A guide to deep learning in healthcare. Nat Med 2019, 25, 24-29, doi:10.1038/s41591-018-0316-z.

5. Ting, D.S.W.; Pasquale, L.R.; Peng, L.; Campbell, J.P.; Lee, A.Y.; Raman, R.; Tan, G.S.W.; Schmetterer, L.; Keane, P.A.; Wong, T.Y. Artificial intelligence and deep learning in ophthalmology. Br J Ophthalmol 2019, 103, 167-175, doi:10.1136/bjophthalmol-2018-313173.

6. Syed, A.B.; Zoga, A.C. Artificial Intelligence in Radiology: Current Technology and Future Directions. Semin Musculoskelet Radiol 2018, 22, 540-545, doi:10.1055/s-0038-1673383.

7. Hosny, A.; Parmar, C.; Quackenbush, J.; Schwartz, L.H.; Aerts, H. Artificial intelligence in radiology. Nat Rev Cancer 2018, 18, 500-510, doi:10.1038/s41568-018-0016-5.

8. Kahn, C.E., Jr. Artificial intelligence in radiology: decision support systems. Radiographics 1994, 14, 849-861, doi:10.1148/radiographics.14.4.7938772.

9. Yasaka, K.; Abe, O. Deep learning and artificial intelligence in radiology: Current applications and future directions. PLoS Med 2018, 15, e1002707, doi:10.1371/journal.pmed.1002707.

10. Tang, A.; Tam, R.; Cadrin-Chênevert, A.; Guest, W.; Chong, J.; Barfett, J.; Chepelev, L.; Cairns, R.; Mitchell, J.R.; Cicero, M.D.; et al. Canadian Association of Radiologists White Paper on Artificial Intelligence in Radiology. Can Assoc Radiol J 2018, 69, 120-135, doi:10.1016/j.carj.2018.02.002.

11. Eltorai, A.E.M.; Bratt, A.K.; Guo, H.H. Thoracic Radiologists' Versus Computer Scientists' Perspectives on the Future of Artificial Intelligence in Radiology. J Thorac Imaging 2020, 35, 255-259, doi:10.1097/rti.0000000000000453.

12. Qurashi, A.A.; Alanazi, R.K.; Alhazmi, Y.M.; Almohammadi, A.S.; Alsharif, W.M.; Alshamrani, K.M. Saudi Radiology Personnel's Perceptions of Artificial Intelligence Implementation: A Cross-Sectional Study. J Multidiscip Healthc 2021, 14, 3225-3231, doi:10.2147/jmdh.S340786.

13. Abuzaid, M.M.; Elshami, W.; McConnell, J.; Tekin, H.O. An extensive survey of radiographers from the Middle East and India on artificial intelligence integration in radiology practice. Health Technol (Berl) 2021, 1-6, doi:10.1007/s12553-021-00583-1.

14. Tajaldeen, A.; Alghamdi, S. Evaluation of radiologist's knowledge about the Artificial Intelligence in diagnostic radiology: a survey-based study. Acta Radiol Open 2020, 9, 2058460120945320, doi:10.1177/2058460120945320.

15. Ooi, S.K.G.; Makmur, A.; Soon, A.Y.Q.; Fook-Chong, S.; Liew, C.; Sia, S.Y.; Ting, Y.H.; Lim, C.Y. Attitudes toward artificial intelligence in radiology with learner needs assessment within radiology residency programmes: a national multi-programme survey. Singapore Med J 2021, 62, 126-134, doi:10.11622/smedj.2019141.

16. Abuzaid, M.M.; Elshami, W.; Tekin, H.; Issa, B. Assessment of the Willingness of Radiologists and Radiographers to Accept the Integration of Artificial Intelligence Into Radiology Practice. Acad Radiol 2022, 29, 87-94, doi:10.1016/j.acra.2020.09.014.

17. Coppola, F.; Faggioni, L.; Regge, D.; Giovagnoni, A.; Golfieri, R.; Bibbolino, C.; Miele, V.; Neri, E.; Grassi, R. Artificial intelligence: radiologists' expectations and opinions gleaned from a nationwide online survey. Radiol Med 2021, 126, 63-71, doi:10.1007/s11547-020-01205-y. 
18. Reznick, R.; Harris, K.; Horsley, T.; Hassani, M. Task Force Report on Artificial Intelligence and Emerging Digital Technologies. Available online: https://www.royalcollege.ca/rcsite/health-policy/initiatives/ai-taskforce-e (accessed on 21/02/2022).

19. Collado-Mesa, F.; Alvarez, E.; Arheart, K. The Role of Artificial Intelligence in Diagnostic Radiology: A Survey at a Single Radiology Residency Training Program. J Am Coll Radiol 2018, 15, 1753-1757, doi:10.1016/j.jacr.2017.12.021.

20. Obermeyer, Z.; Emanuel, E.J. Predicting the Future - Big Data, Machine Learning, and Clinical Medicine. N Engl J Med 2016, 375, 1216-1219, doi:10.1056/NEJMp1606181.

21. Hall, G.E.; Dirksen, D.J.; George, A.A. Measuring implementation in schools: Levels of use; Southwest Educational Development Laboratory: 2006.

22. Lai, P.C. The literature review of technology adoption models and theories for the novelty technology. JISTEMJournal of Information Systems and Technology Management 2017, 14, 21-38, doi:10.4301/S1807-17752017000100002.

23. Khafaji, M.A.; Safhi, M.A.; Albadawi, R.H.; Al-Amoudi, S.O.; Shehata, S.S.; Toonsi, F. Artificial intelligence in radiology: Are Saudi residents ready, prepared, and knowledgeable? Saudi Med J 2022, 43, 53-60, doi:10.15537/smj.2022.43.1.20210337.

24. Lee, L.I.T.; Kanthasamy, S.; Ayyalaraju, R.S.; Ganatra, R. The Current State of Artificial Intelligence in Medical Imaging and Nuclear Medicine. BJR Open 2019, 1, 20190037 , doi:10.1259/bjro.20190037.

25. Scheetz, J.; Rothschild, P.; McGuinness, M.; Hadoux, X.; Soyer, H.P.; Janda, M.; Condon, J.J.J.; Oakden-Rayner, L.; Palmer, L.J.; Keel, S.; et al. A survey of clinicians on the use of artificial intelligence in ophthalmology, dermatology, radiology and radiation oncology. Sci Rep 2021, 11, 5193, doi:10.1038/s41598-021-84698-5.

26. Ryan, M.L.; O'Donovan, T.; McNulty, J.P. Artificial intelligence: The opinions of radiographers and radiation therapists in Ireland. Radiography (Lond) 2021, 27 Suppl 1, S74-s82, doi:10.1016/j.radi.2021.07.022. 